\title{
2015: which new directions for Alzheimer's disease?
}

\section{Xénia Latypova and Ludovic Martin*}

Université de Nantes, Nantes, France

${ }^{*}$ Correspondence: Imartin.phd@gmail.com

Edited and reviewed by:

Egidio D'Angelo, University of Pavia, Italy

Keywords: Alzheimer's disease (AD), dementia, tau, abeta, therapeutics

Around 44 million people in the world are suffering from dementia including Alzheimer's disease (AD). It is considered as one of the biggest global public health challenges our generation cope with. At the dawn of 2015, AD medical care remains unsuccessful despite the identification of its neuropathological hallmarks one century ago. Being attentive to emerging prospects is essential because the current advances lead to substantive improvement of the medical care. We are pleased to present an issue specifically devoted to $\mathrm{AD}$ and to the related therapeutic strategies. The Topic Research in this issue is based on a series of original papers and reviews. The latters focus on the advances in basic and clinical research trends in $\mathrm{AD}$, they provide an up-to-date information and future perspectives on this hot topic as well.

$\mathrm{AD}$ is a progressive disease, it occurs over a long period before the onset of symptoms which are impaired memory, apathy, and depression. The characteristics of $\mathrm{AD}$ consist in neurofibrillary tangles (intraneuronal aggregates of hyperphosphorylated tau proteins) and senile plaques [dense extraneuronal deposits composed of amyloid $\beta(A \beta)$ ]. The other features linked to these two core pathological hallmarks of $\mathrm{AD}$ are inflammation, oxidative stress, progressive synaptic, and neuronal loss. Nowadays, many $\mathrm{AD}$ molecular patterns have been screened to identify a potential therapeutic strategy. Although a myriad of evidence shows that the hippocampal volume decrease belongs to the $\mathrm{AD}$ earliest signs, as it is pointed out by the authors of the review paper presented in this issue, this element clearly could not be used as a diagnostic criterion (Maruszak and Thuret, 2014).

With the flood of evidence for tau pathology as key event of the disease development, the understanding of diverse tau functions and its molecular behavior is one of the major steps in the progression of our knowledge about the neurodegenerescence detected in AD. The precision of tau role in DNA protection and RNA integrity under physiological conditions or under ROSproducing stress (Violet et al., 2014) provides clarification for a mechanistic model in which tau disturbance initiates an explanation for DNA damages observed in AD. Principally, tau is a phosphoprotein. So, a complex equilibrium between tau kinases and phosphatases activities is one of the main potential therapeutic runways. Abnormal or excessive tau phosphorylation by either kinases such as GSK3 $\beta$, CDK5, DYRK1A for example or other known and unknown kinases are related to $\mathrm{AD}$ pathogenesis. However, the identity and the strict number of tau kinases involved in $\mathrm{AD}$ process remain uncertain. In this way, focus at specific tau phosphorylation site(s) by a kinase multitargeting approach as potential AD therapeutic strategy has been proposed to effectively hamper the multifactorial disease progression (Hilgeroth and Tell, 2013). Since diabetes, linked itself to dysregulation of GSK3 $\beta$ activity, is associated in latelife with an increased risk of dementia, epidemiological and experimental studies are summarized in this issue in order to understand the effects of diabetes mellitus on tau pathogenesis. In fact, the authors discuss herein a link between tau, diabetes mellitus and the cognitive impairment (El Khoury et al., 2014). On the other hand, Peptidyl-prolyl cis-trans Isomerase NIMA-interacting 1 (Pin1), which plays a role in the balance of phosphorylation/dephosphorylation of tau, has been suspected of participating in a common mechanism between $\mathrm{AD}$ and hypoxia. The pathophysiological relevance of Hypoxia-inducible factor $1 \alpha$ (HIF-1 $\alpha$ ) pathway regulation in APP amyloidogenic metabolism has been explored in order to clarify the relationship between $\mathrm{AD}$ and hypoxia (Lonati et al., 2014). Among tau-based therapeutic strategies, the one which limits the spreading of tau pathology without affecting tau intracellular functions is especially attractive (Medina and Avila, 2014). Strong support for this idea comes from the importance of tau for $A \beta$-induced synaptotoxicity. In addition to this, high concentration of $A \beta$ inhibits synaptic activity and in turn, it involves toxicity for the targeted synapses (Wang et al., 2013). According to this strategy, synaptic inhibitory systems could help to compensate neurotransmission imbalance (Nava-Mesa et al., 2014). Moreover, natural anti-inflammatory components, as Andrean Compound, has been studied as a preventive or adjuvant agent in $\mathrm{AD}$ (Maccioni et al., 2014).

Accumulation of $A \beta$ is induced when the equilibrium between its production and clearance is disrupted. Thus, amyloid-based therapeutic strategies target this balance but numerous trials were unsuccessful for reasons of specificity or biodisponibility. However, the restoration of the microglial homeostasy and the targeting of Triggering Receptor Expressed on Myeloid cells 2 (TREM2) pathway can constitute an elegant therapeutic strategy (Zhao and Lukiw, 2013). Compounds are yet available to improve the microglia-dependent clearance of $A \beta$, and this strategy would benefit from in vivo experiments (Jones et al., 2014). Furthermore, diversity of gut microbiota changes through life stages and alterations of this ecosystem have been associated with diverse diseases. Therapeutic modulation of gut microbiota could constitute a promising adjuvant therapy in central neurodegenerative disorders. An opinion article proposes probiotics as a prophylactic treatment to prevent $\mathrm{AD}$ in its early stages (Bhattacharjee and Lukiw, 2013). 
Several recent key advances in the field of $\mathrm{AD}$ understanding and treatment are presented in this thematic issue. Ultimately, we hope that you will enjoy as us to read these papers and reviews presented in this special issue. The coming years certainly promise a time for completion of a new era in the history of the AD understanding and emerging therapies. AD understanding is within reach. Stay tuned.

\section{ACKNOWLEDGMENT}

This editorial article was edited by Mrs. Souad Kaci.

\section{REFERENCES}

Bhattacharjee, S., and Lukiw, W. J. (2013). Alzheimer's disease and the microbiome. Front. Cell. Neurosci. 7:153. doi: 10.3389/fncel.2013.00153

El Khoury, N., Gratuze, M., Papon, M.-A., Bretteville, A., and Planel, E. (2014). Insulin dysfunction and Tau pathology. Front. Cell. Neurosci. 8:22. doi: 10.3389/fncel.2014.00022

Hilgeroth, A. P., and Tell, V. (2013). Recent developments of protein kinase inhibitors as potential AD therapeutics. Front. Cell. Neurosci. 7:189. doi: 10.3389/fncel.2013.00189

Jones, B. M., Sethi-Dua, P., Zhao, Y., Bhattacharjee, S., Hill, J. M., and Lukiw, W. (2014). Regulating amyloidogenesis through the natural triggering receptor expressed in myeloid/microglial cells 2 (TREM2). Front. Cell. Neurosci. 8:94. doi: $10.3389 /$ fncel.2014.00094

Lonati, E., Brambilla, A., Milani, C., Masserini, M., Palestini, P., and Bulbarelli, A. (2014). Pin1, a new player in the fate of HIF- $1 \alpha$ degradation: an hypothetical mechanism inside vascular damage as Alzheimer's disease risk factor. Front. Cell. Neurosci. 8:1. doi: 10.3389/fncel.2014.00001

Maccioni, R. B., Morales, I., Guzman-Martinez, L., Cerda-Troncoso, C., and Farías, G. A. (2014). Neuroinflammation in the pathogenesis of Alzheimer's disease. A rational framework for the search of novel therapeutic approaches. Front. Cell. Neurosci. 8:112. doi: 10.3389/fncel.2014.00112

Maruszak, A., and Thuret, S. P. (2014). Why looking at the whole hippocampus is not enough - a critical role for anteroposterior axis, subfield and activation analyses to enhance predictive value of hippocampal changes for Alzheimer's disease diagnosis. Front. Cell. Neurosci. 8:95. doi: 10.3389/fncel.2014. 00095

Medina, M., and Avila, J. (2014). The role of extracellular Tau in the spreading of neurofibrillary pathology. Front. Cell. Neurosci. 8:113. doi: $10.3389 /$ fncel.2014.00113

Nava-Mesa, M. O., Jiménez-Díaz, L., Yajeya, J., and Navarro-Lopez, J. D. (2014). GABAergic neurotransmission and new strategies of neuromodulation to compensate synaptic dysfunction in early stages of Alzheimer's disease. Front. Cell. Neurosci. 8:167. doi: 10.3389/fncel.2014.00167

Violet, M., Delattre, L., Tardivel, M., Sultan, A., Chauderlier, A., Caillierez, R., et al. (2014). A major role for Tau in neuronal DNA and RNA protection in vivo under physiological and hyperthermic conditions. Front. Cell. Neurosci. 8:84. doi: 10.3389 /fncel.2014.00084

Wang, Y., Zhou, T. H., Zhi, Z., Barakat, A., Hlatky, L., and Querfurth, H. (2013). Multiple effects of $\beta$-amyloid on single excitatory synaptic connections in the PFC. Front. Cell. Neurosci. 7:129. doi: 10.3389/fncel.2013.00129

Zhao, Y., and Lukiw, W. (2013). TREM2 signaling, miRNA-34a and the extinction of phagocytosis. Front. Cell. Neurosci. 7:131. doi: 10.3389/fncel.2013. 00131

Conflict of Interest Statement: The authors declare that the research was conducted in the absence of any commercial or financial relationships that could be construed as a potential conflict of interest.

Received: 20 September 2014; accepted: 17 November 2014; published online: 09 December 2014.

Citation: Latypova X and Martin L (2014) 2015: which new directions for Alzheimer's disease? Front. Cell. Neurosci. 8:417. doi: 10.3389/fncel.2014.00417

This article was submitted to the journal Frontiers in Cellular Neuroscience.

Copyright (C) 2014 Latypova and Martin. This is an open-access article distributed under the terms of the Creative Commons Attribution License (CC BY). The use, distribution or reproduction in other forums is permitted, provided the original author(s) or licensor are credited and that the original publication in this journal is cited, in accordance with accepted academic practice. No use, distribution or reproduction is permitted which does not comply with these terms. 